\title{
Mandibular advancement reveals long-term suppression of breathing discomfort in patients with obstructive sleep apnea syndrome
}

Valérie ATTALI, MD, PHD ${ }^{\mathrm{a}, \mathrm{b}^{*}}$; Jean-Marc COLLET MD ${ }^{\mathrm{b}, \mathrm{c}}$; Olivier JACQ DO ${ }^{\mathrm{b}}$; Sandie SOUCHET PHD ${ }^{\mathrm{d}}$; Isabelle ARNULF, MD, PHD ${ }^{\mathrm{b}}$; Isabelle RIVALS, PHD ${ }^{\mathrm{a}, \mathrm{e}}$; Jean-Baptiste KERBRAT, MD ${ }^{\mathrm{c}, \mathrm{f}}$; Patrick GOUDOT, MD, PHD ${ }^{\mathrm{c}, \text {; }}$; Capucine MORELOT-PANZINI MD, PHD $^{\mathrm{a}, \mathrm{g}}$; Thomas SIMILOWSKI, MD, PHD ${ }^{\mathrm{a}, \mathrm{g}}$

${ }^{a}$ Sorbonne Université, INSERM, UMRS1158 Neurophysiologie Respiratoire Expérimentale et Clinique, F-75005 Paris, France

${ }^{\mathrm{b}}$ AP-HP, Groupe Hospitalier Pitié-Salpêtrière Charles Foix, Service des Pathologies du Sommeil (Département "R3S"), F-75013 Paris, France.

c

${ }^{\mathrm{d} U n i v e r s i t e ́ ~ P a r i s ~ I ~-~ P a n t h e ́ o n-S o r b o n n e, ~ l a b o r a t o i r e ~ S A M M ~(S t a t i s t i q u e, ~ A n a l y s e, ~}$ Modélisation Multidisciplinaire -EA4543), F-75005 Paris, France

${ }^{\mathrm{e}}$ Equipe de Statistique Appliquée, ESPCI Paris, PSL Research University F-75005 Paris, France.

fSorbonne Université, UMR 8256 B2A, F-75005, Paris, France

${ }^{g}$ AP-HP, Groupe Hospitalier Pitié-Salpêtrière Charles Foix, Service de Pneumologie, Médecine Intensive et Réanimation (Département "R3S"), F-75013, Paris, France

Electronic adresses

Valérie Attali : valerie.attali@aphp.fr ; Jean-Marc Collet : jeanmarc.collet2a@gmail.com; Olivier Jacq : jacqolivier.osteo@gmail.com; Sandie Souchet : sandie.souchet@univ-paris1.fr ; Isabelle Arnulf : isabelle.arnulf@aphp.fr; Isabelle Rivals : isabelle.rivals@espci.fr; JeanBaptiste Kerbrat : kerbratjb@wanadoo.fr; Patrick Goudot : patrick.goudot@aphp.fr; Capucine Morelot-Panzini : capucine.morelot@aphp.fr ;Thomas Similowski:

thomas.similowski@aphp.fr

Corresponding author

Dr Valérie ATTALI

valerie.attali@aphp.fr

Département R3S Service des Pathologies du Sommeil

Groupe Hospitalier Pitié-Salpêtrière

47 boulevard de l'hôpital

75013 Paris

Phone : + 33142167730

Fax : +33142167700 


\section{Abstract}

Obstructive sleep apnoea syndrome (OSAS) patients do not report breathing discomfort in spite of abnormal upper airway mechanics. We studied respiratory sensations in OSAS patients without and with mandibular advancement device (MAD).

Fifty-seven moderate to severe non obese OSAS patients were asked about breathing discomfort using visual analogue scales (VAS) in the sitting position (VAS-1), after lying down (VAS-2), then with MAD (VAS-3). Awake critical closing pressure (awake Pcrit) was measured in 15 patients without then with MAD.

None of the patients reported breathing discomfort when sitting but 19 patients (33\%) did when lying (VAS-2: $-20 \%$ or less). A feeling of "easier breathing" with MAD was observed and was more marked in patients reporting breathing discomfort when supine (VAS-3: +66.0\% [49.0; 89.0]) than in those not doing so (VAS-3: $+28.5 \%[1.0 ; 56.5], \mathrm{p}=0.007)$. MAD-induced change in awake Pcrit was correlated to VAS-3.

In conclusion, MAD revealed "latent dyspnea" related to the severity of upper airways mechanics abnormalities in OSAS patients.

\section{Key words}

Obstructive sleep apnoea syndrome; mandibular advancement device; breathing discomfort; latent dyspnoea; gating out; sensory habituation. 


\section{Introduction}

The obstructive sleep apnoea syndrome (OSAS) is characterized by recurrent episodes of upper airway obstruction that interrupt ventilation during sleep (Jordan et al., 2014). OSAS is associated with increased upper airway resistance and collapsibility during sleep (Gold et al., 2002) but also while awake (Lin et al., 2004; Verin et al., 2002) that constitute mechanical constraints to inspiration (inspiratory loading). Compensatory mechanisms such as increased baseline activity of upper airway dilators (Mezzanotte et al., 1992) and increased resting diaphragmatic activity (Steier et al., 2010), prevent upper airway collapse during wakefulness. Peripheral neurogenic changes leading to increased multiunit electromyographic signal may partly explain the increased baseline activity of the genioglossus while awake (Saboisky et al., 2007) however some of these compensatory mechanisms are cortical in nature (Series et al., 2009), including a respiratory-related premotor and motor cortical activity (Launois et al., 2015). Increased inspiratory load due to abnormal upper airways mechanics, increased neural ventilatory drive, and respiratory-related cortical activation are generally associated with breathing discomfort or dyspnea. This has been verified experimentally (Morawiec et al., 2015; Raux et al., 2007) and in various clinical contexts, like chronic obstructive pulmonary disease (COPD) (Jolley et al., 2015), idiopathic pulmonary fibrosis (Bonini and Fiorenzano, 2017), cystic fibrosis (Reilly et al., 2011), laryngeal obstruction (Walsted et al., 2018), or amyotrophic lateral sclerosis (Georges et al., 2016). Yet OSAS patients typically do not complain spontaneously from breathing discomfort at rest. This constitute a clinical abnormality even though it is plausible that OSAS-related inspiratory loading is smaller in magnitude than the loading associated with other respiratory disorders.

Repeated and sustained exposure to aversive respiratory stimuli can result in habituation, a process that blunts or suppress the corresponding respiratory sensations. This has been demonstrated experimentally (Subhan et al., 2003; von Leupoldt et al., 2011; Wan et al., 
2009) and suspected clinically (Kikuchi et al., 1994; Reilly et al., 2016). Habituation could proceed, at least in part, from downregulation of the insular cortex (Stoeckel et al., 2015; von Leupoldt et al., 2009). It could also proceed from altered somatosensory processing of respiratory stimuli (Davenport et al., 2000; Fauroux et al., 2007), a phenomenon that can be present in OSAS patients (Donzel-Raynaud et al., 2009; Grippo et al., 2011). Habituation could therefore explain why OSAS patients do not complain from dyspnea. Of note, this is clinically relevant because dyspnea is a strong incentive to seek medical attention: its absence in OSAS patient could contribute to delay diagnosis and treatment.

Mandibular advancement devices (MAD) enlarge and stabilize the upper airway and induce reduction of upper airway resistance in awake OSAS patients (Gakwaya et al., 2014). They constitute a valid alternative to continuous positive airway pressure (CPAP), the reference treatment of OSAS (Bratton et al., 2015). From anecdotal clinical observations, we hypothesized that habituation to dyspnea would result in a sensation of "easier breathing" with MAD in OSAS patients not complaining from dyspnea during resting breathing. We therefore undertook the present study to: 1) verify this hypothesis by systematically studying respiratory sensations in OSAS patients in the sitting position, the supine position, and with MAD; 2) test the secondary hypothesis that the sensation of easier breathing induced by MAD relates with the severity of upper airway mechanical abnormalities.

\section{Materials and Methods}

The study was conducted in accordance with the Declaration of Helsinki. The protocol was approved on October 222014 by the ethics committee of the French national sleep medicine society (Société Française de Recherche et Médecine du Sommeil). The patients received detailed information and provided their written consent to participate. OSAS patients participated in the two substudies. Non-OSAS patients (see below) participated only in study 1 , to serve as controls. 


\subsection{Study 1: systematic description of the effects of MAD on breathing sensations}

\subsubsection{OSAS patients population}

OSAS patients were selected among patients referred to the sleep medicine department of our institution and in whom the diagnosis was confirmed by a full-night polysomnography according to standard procedures; respiratory events were measured during a full-night polysomnography according to the international guidelines (Berry et al., 2012). On a period of 6 months, we consecutively studied all patients with a diagnosis of OSAS selected for MAD on the basis of standard criteria (namely: AHI $\geq 15 / \mathrm{h}$, severe daytime sleepiness, intolerance to or refusal of continuous positive airway pressure (CPAP) therapy, at least eight healthy teeth per jaw, absence of periodontal disease or temporomandibular joint disease) (Marklund et al., 2012) ( $\mathrm{n}=57$; table 1). All patients were naïve of MAD treatment. Exclusion criteria were any underlying neurological, respiratory or cardiac disease possibly associated with dyspnoea or with altered central neural processes.

\subsubsection{Non-OSAS patients population}

Twelve patients referred to our department to investigate suspected hypersomnia $(n=7)$, non REM parasomnia $(n=2)$, restless legs syndrome $(n=1)$ or REM sleep behavior disorder $(n=1)$ were studied. A full-night polysomnography confirmed that they were free of OSAS (table 1).

\subsubsection{Mandibular advancement devices}

In the OSAS patients, two MAD were used, both consisting of custom-made bi-block titratable device (Narval $^{\mathrm{TM}}$, ResMed, Saint-Priest, France; Somnodent ${ }^{\mathrm{TM}}$, SomnoMed Ltd., Sydney, Australia). The MAD was fitted and titrated at one or more visits (median number of 
titration visits was 2 [1-2]) by the dental sleep specialist. During each titration visit, patients were firstly asked about OSA symptoms. Then the MAD was titrated in the supine position, $\mathrm{mm}$ by $\mathrm{mm}$, starting at $50 \%$ of the patient's maximum mandibular protrusion, by replacing the connecting rod by the immediately smaller one for the NarvalTM and by advancing the screw by $1 \mathrm{~mm}$ for the Somnodent ${ }^{\mathrm{TM}}$. Between titration visits patients were encouraged to use their MAD several hours during several days at home. Mandibular advancement was of $67 \%$ [60; 71] at the first level of titration and $80 \%[75 ; 89]$ at the last level of titration $(\mathrm{p}<0.00001)$ without any difference between Somnodent ${ }^{\mathrm{TM}}$ and Narval ${ }^{\mathrm{TM}}$ sub-groups (respectively $86 \%[68 ; 88]$ and $83 \%[76 ; 90](\mathrm{p}=0.656))$.

In the non-OSAS patients mandibular advancement was performed one $\mathrm{mm}$ at a time with the BluePro® titratable thermoplastic device (BlueSom, Orvault, France) (Gagnadoux et al., 2017), to $100 \%$ of the subject's maximum active protrusion (median: $6.5 \mathrm{~mm}$ [6.0-7.0]).

At each level of mandibular advancement, OSAS and non-OSAS patients were asked about MAD comfort.

The three devices used in this study cover only the maxillary and the mandible and nothing constraints tongue mobility. The respective volumes of the devices were assessed using a micro-computed tomography (micro-CT) ( $\mu$ CT100 Scanco Medical Brüttisellen Switzerland). They were of $7.3,12.1$ and $13.8 \mathrm{ml}$ respectively for the $\mathrm{Narval}^{\mathrm{TM}}$, the Somnodent $^{\mathrm{TM}}$ and the BluePro® MAD (see supplemental material).

\subsubsection{Psychophysiological evaluation of breathing discomfort (see figure 1)}

This evaluation was done at the last titration visit. Patients were firstly asked about OSA symptoms and MAD comfort. Then, the participants were asked to positively or negatively answer an open question about the presence of breathing discomfort at rest. Irrespective of the 
answer, they were then asked to rate their breathing discomfort on a non-graduated $100-\mathrm{mm}$ visual analogue scale anchored by "no breathing discomfort" at the left end, and "intolerable breathing discomfort" at the right end ("baseline" scale ; results expressed in \% full scale; VAS1 dataset). The patients were told that in case of a negative answer to the open question, they could choose "no breathing discomfort" on the scale but that they could also choose otherwise, the two assessments being independent. VAS-1 was first applied with the patients seated in a comfortable chair, and then reapplied after they had assumed a fully supine position (VAS1seated dataset and VAS-1supine dataset, respectively). A second non graduated 100-mm visual analogue scale was used to evaluate the changes in breathing comfort (in either direction) between the sitting and the supine positions ("transitional" scale; from "extreme deterioration" on the left end to "extreme improvement" on the right, with a middle marker to indicate "no change"; the results are expressed in percentage of the full scale, the latter being defined as the distance between the central landmark and either of the extremes, with a "+" sign for improvement and a "-" sign for deterioration; VAS-2dataset). With the patients remaining supine the MAD was fitted and mandibular advancement was titrated. The transitional scale was then used again to evaluate the changes in breathing comfort at the end of titration (VAS3 data set).

\subsection{Study 2: relationship between MAD-induced changes in respiratory sensations and awake critical closing pressure (awake Pcrit).}

This study was conducted in a subset of 15 of the 57 OSAS patients. The airway pressure/flow relationship was established to determine the awake critical closing pressure (awake Pcrit), defined as the negative pressure that induces closure of the upper airways (absence of air flow). Awake Pcrit was determined while awake according to the method validated by Su et al. (Su et al., 2008) and measured as described previously (Jacq et al., 2017; Patil et al., 2004; Schwartz et al., 1988; Su et al., 2009). The patients were installed in the supine 
position with the head resting in a neutral position on a flat pillow. The position of the head was maintained with a foam collar and patients were instructed to relax them and to breathe naturally exclusively through the nose. A nasal mask was applied and connected to a circuit allowing the generation of an increasingly negative pressure. Six negative pressure $(-0.3,-0.9,-2.5,-6,-10$, $-13 \mathrm{cmH} 2 \mathrm{O})$ were abruptly applied consecutively. Each negative pressure was applied at the end of a natural expiration for five to ten cycles, followed by a 60 -second period of rest at the atmospheric pressure. An habituation measure was followed by two similar series of negative pressure for the awake Pcrit assessment. Airflow and pressure in the mask were measured by a pneumotachograph (Hans Rudolph Model 4700; Hans Rudolph, Inc., Kansas City, MO). At each level of negative pressure, the second and the third breath after applying the negative pressure were examined. Awake Pcrit was then estimated, as the nasal pressure at zero flow, by linear regression, plotting pressure against flow values, measured from cycles with apparent inspiratory flow limitation, at each imposed pressure phase (Patil et al., 2004).

\subsection{Statistical analysis}

Data are expressed as medians and interquartile ranges. Continuous variables were compared with Mann-Whitney's test and proportions were compared by Fisher's exact test.

Regarding study 1, multivariate logistic regression was used to identify the factors associated with a variation of VAS-3 $\geq 20 \%$. First, each potential factor was evaluated in a univariate comparison between patients meeting this criterion and patients not meeting it. Except when redundant with other factors, factors yielding $p$-values $\leq 0.20$ were considered for a stepwise logistic regression, either forward or backward. All tests were two-tailed, and pvalues $<0.05$ were considered statistically significant. The Hosmer-Lemeshow chi-square test was used to assess the goodness-of-fit of the final model. Odds ratios (ORs) and their 95\% confidence interval were computed for the significant factors. The area under the receiver operating characteristic curve (AUC) was used to evaluate the discriminative power of the 
models. The logistic regressions were performed using MatlabTM (Natick, MA, USA) version 9.1.0.441655 (R2016b) and its Statistics Toolbox version 10.0.

Regarding study 2, associations between VAS and awake Pcrit were evaluated using Spearman's correlation coefficient.

\section{Results}

\subsection{Study 1: systematic description of the effects of MAD on breathing sensations}

None of the OSAS patients reported resting respiratory discomfort when sitting, either spontaneously or when prompted by an open "yes-no" question. The corresponding median VAS-1 rating was $3 \%$ of full scale $[0.0 ; 10.0])$. Supine VAS-1 scores were significantly higher than sitting scores $(10.0 \%$ full scale $[2.0 ; 23.0], \mathrm{p}=0.00007)$. The median VAS-2 was of $0.0 \%$ $[-27.0 ; 0.0]$ but 19 patients $(33 \%)$ reported deteriorated breathing comfort defined by a $-20 \%$ or more negative values on VAS-2 (figure 2). Mandibular advancement was generally associated with a subjective impression of "easier breathing", with VAS-3 scores showing a 30\% improvement $[0 ; 50]$ at the first level and $42 \%[6 ; 76]$ at the last level of titration (first versus last level, $\mathrm{p}=0.007)$. This figure for the last level of titration was $66.0 \%[49.0 ; 89.0]$ in the 19 patients who reported a deterioration of breathing comfort when lying supine and $28.5 \%$ [1.0; 56.5 ] in the 38 others $(\mathrm{p}=0.007$ ) (figure 3 ). Note that there was no significant difference on VAS-3 score between patients using the Somnodent ${ }^{\mathrm{TM}}$ and patient using the Narval ${ }^{\mathrm{TM}}$ (respectively $50 \%[33 ; 57]$ and $34 \%[5 ; 75] ; \mathrm{p}=0.785$ ).

None of the non-OSAS patients reported respiratory discomfort at rest in either the sitting or supine positions and they consistently rated 0 on the VAS-1 scale, both sitting and supine. Their median VAS-3 score after mandibular advancement was $0 \%$ [-21.0; 9.0], with a majority of patients tending to consider their breathing to be less comfortable with mandibular 
advancement than without (in complete contrast with OSAS patients, who never reported worsening).

Univariate analysis identified several variables that differed significantly between the patients who reported an improvement of $20 \%$ of full scale or more on VAS-3 $(n=37)$ and the patients who did not $(\mathrm{n}=20)$ (table 2). Backward and forward logistic regression led to same final logistic model with an AUC of $84.1 \%$. Two factors were retained as independent predictors of MAD-related improvement in breathing comfort: maximal mouth opening (in $\mathrm{mm}$ ) (odds ratio $[\mathrm{OR}] 1.24,95 \%$ confidence interval $[\mathrm{CI}] 1.07-1.44 ; \mathrm{p}=0.0039$; the wider the maximal mouth opening, the higher the probability of MAD-related improvement) and supine VAS-1 (OR 1.06, 95\% CI 1.01-1.12; $\mathrm{p}=0.025$; the higher supine VAS-1, the higher the probability of improvement)

\subsection{Study 2: relationship between MAD-induced changes in respiratory sensations and awake critical closing pressure (awake Pcrit).}

In the 15 patients where awake Pcrit was measured, baseline awake Pcrit was of -15.8 [-18.0; 5.0] $\mathrm{cm} \mathrm{H}_{2} 0$ and awake Pcrit with MAD was of -16.6 [-23.8; -9.3] $\mathrm{cm} \mathrm{H}_{2} 0$ (difference -5.4 [$8.2 ;-2.6]$ in favour of a better stability of the upper airways, but not significant; $p=0.065)$. A significant correlation was however observed between the reduction in awake Pcrit induced by MAD (improved upper airway stability) and the corresponding improvement in breathing comfort evaluated with VAS-3 (Spearman's $\mathrm{r}=0.81,95 \%$ CI $0.52-0.94, \mathrm{p}<10^{-4}$ ) (Figure 4).

\section{Discussion}

This study confirms the empirical notion that OSAS patients do not perceive significant breathing discomfort at rest in the sitting position, spontaneously of after being prompted (but breathing discomfort can appear in the supine posture). Yet OSAS patients not complaining from dyspnea described a feeling of breathing more easily in response to MAD, the intensity of 
which correlated with the degree of improvement of upper airway stability as assessed by the measurement of awake Pcrit. We submit that this supports the existence of habituation as an explanation to the lack of breathing discomfort at rest in OSAS patients.

\subsection{MAD-associated breathing improvement and upper airway mechanical properties}

Going from the sitting to the supine position deteriorates upper airway mechanical properties and patency (Ingman et al., 2004; Penzel et al., 2001). Conversely, MAD improves upper airway mechanical properties during sleep (Kato et al., 2000) and during wakefulness (Bosshard et al., 2011; Gakwaya et al., 2014). Our observations are fully in line with these data: in our OSAS patients, breathing comfort deteriorated when lying down and improved on MAD. This suggests a direct relationship between upper airway anatomy and mechanics and respiratory sensations. This is supported by the results of the multivariate analysis showing that maximal mouth opening, an anatomic factor, was an independent predictor of the MAD-related improvement in breathing comfort. This was confirmed by the correlation between the magnitude of the MAD-related decrease in awake Pcrit and the MAD-related improvement in breathing discomfort (Figure 4). This is also independently supported by the absence of deterioration of breathing comfort when lying down and the absence of improvement on MAD in controls.

\subsection{Blunted respiratory sensations in OSAS patients}

Respiratory sensations arise from one or several stimuli, the transmission of these stimuli to the brain, and cognitive and affective processing of the corresponding sensory information. In OSAS patients, several types of neural lesions could interfere with this process and explained both blunted perception of inspiratory resistive loading (Tun et al., 2000) and our present results. These lesions include peripheral pharyngeal neuropathy (Sunnergren et al., 2011; Tsai et al., 2013) that could blunt the perception of respiratory abnormalities in the same 
way as it blunts the perception of mucosal airflow (Dematteis et al., 2005) or the perception of cold (Sunnergren et al., 2011). Central nervous system lesions could also interfere with the central processing of respiratory stimuli. Likewise diffuse gray matter loss has been described (Harper et al., 2012; Macey et al., 2002; Rosenzweig et al., 2015). In addition, abnormal brain responses to inspiratory loading have been described (Macey et al., 2006) and a recent study relying on magnetic resonance spectroscopy data has shown altered anterior insular levels of GABA and glutamate that may modify the brain processing of aversive respiratory stimuli (Macey et al., 2016). However, we believe that the immediate changes in respiratory sensations reported by our patients in response to MAD indicate that peripheral or central neural lesions cannot constitute the sole explanation of their suppressed respiratory sensations. This fast dynamics, consistent with the immediate MAD-induced improvement of upper airway mechanics advancement (Gakwaya et al., 2014; Sam et al., 2006; Verin et al., 2006), is compatible with a respiratory ungating mechanism or, in other words, with an habituation process. In normal subjects, subjective habituation of respiratory perception has been paralleled by objective habituation of the neural processing of respiratory stimuli (von Leupoldt et al., 2011). In this study, the magnitude of respiratory-related evoked potentials elicited by inspiratory occlusions was reduced between early and late experimental periods in healthy subjects (von Leupoldt et al., 2011). In this regard, it is interesting to note that several studies have evidenced abnormal respiratory-related evoked potentials in OSAS patients (DonzelRaynaud et al., 2009; Grippo et al., 2011). These abnormalities could possibly be the results of habituation.

Another phenomenon that could contribute to explain our observations would be the activation of respiratory relief neural circuits by MAD. Such circuits have been described in inspiratory loading experiments conducted in normal subjects (Peiffer et al., 2008). In these 
experiments, dyspnea relief was associated not only with the deactivation of load-activated networks, but also with the activation of a specific network (Peiffer et al., 2008).

The magnitude of VAS-3 related breathing comfort improvement on MAD (the $42 \%$ observed improvement corresponds to $21 \mathrm{~mm}$ ) was higher than the VAS-related dyspnoea improvement previously described in acute heart failure (Pang et al., 2017). In this study a 10.5 $\mathrm{mm}$ change in VAS in the upright position, and $14.5 \mathrm{~mm}$ in the supine position were considered as minimal clinically important differences within six hours after initiation of treatment. This indicates that breathing discomfort related to abnormal upper airway mechanics in our patients, although masked was clinically relevant. Of note similar amplitudes were observed in the supine position on VAS-1 (50\% of patients reported a breathing discomfort higher than $10 \mathrm{~mm}$ ) and VAS-2 (33\% of patients reported a $20 \%$ i.e. $10 \mathrm{~mm}$ improvement in breathing discomfort).

\subsection{Study limitations}

We acknowledge that several elements can limit the generalisability of our results: the study population is of limited size and had to be determined empirically in the absence of previous data on respiratory sensations in OSAS; in addition, we focused on OSAS patients free of any associated respiratory or cardiac disorder, frequent conditions which are liable to interfere with respiratory sensations. Even questionable as they were trying a new treatment for the first time, patients had probably none expectation about breathing improvement while not complaining from any breathing difficulties. Moreover at each visit they were asked firstly about their symptoms and MAD comfort and their attention was not focussed only on breathing comfort at any time. Eighteen patients (32\%) were obese that would be factor of deteriorated breathing comfort while lying, however the majority (13 patients) had a BMI $<35 \mathrm{~kg} / \mathrm{m}^{2}$ which represents mild obesity. We also acknowledge that our control group was not matched to the index group, that we did not randomly compare several levels of mandibular advancement, and that we did not use a placebo control procedure with which to compare the effects of MAD. 
However there was no significant difference between patients and controls in terms of BMI and age. We believe that the complete divergence between the behaviour of our OSAS and control patients (even without MAD), as well as the significant relationship between MAD-induced breathing comfort improvement and awake Pcrit, are strong arguments against a placebo effect of MAD. In addition, in OSAS patients there was a significant improvement in breathing comfort from the first to the last level of titration, which is in favour of a "dose-effect" in MADinduced breathing comfort. Of note, a similar dose-effect was previously shown for MADinduced pharyngeal stability (Kato et al., 2000), which is in line with the correlation observed in our study between awake Pcrit and magnitude of mandibular advancement. We are therefore convinced that our observations are correct.

Though we used two different custom-made devices in the OSAS group, and the Somnodent ${ }^{\mathrm{TM}}$ was slightly larger than the Narval ${ }^{\mathrm{TM}}$. However, we are confident that our results were not volume dependent since there was no difference between both devices in terms of mandibular advancement and related breathing comfort. Note that both devices have previously demonstrated similar efficacy and tolerability in the treatment of OSAS (Milano et al., 2013; Vecchierini et al., 2016; Verburg et al., 2018). In controls, we used a titratable thermoplastic device for regulatory reasons (in France custom-made devices are not considered in non OSAS patients). The BluePro ${ }^{\circledR}$ is as retentive (Braem, 2015) has a similar volume and is well-tolerated in terms of mouth comfort as the Somnodent ${ }^{\mathrm{TM}}$ (Gagnadoux et al., 2017). The three devices used in this study cover only the maxillary and the mandible (nothing constraints tongue mobility) which limits intra oral volume and volume-related breathing sensations.

Perhaps more importantly from a physiological point of view, we did not quantify the respiratory neural drive to breathe in our patients. Future studies will be necessary to characterize this aspect of the phenomenon that we describe. In particular, it will be interesting to characterize putative relationships between the unmasking of respiratory discomfort by MAD 
and OSAS-related activation of cortical respiratory networks (Launois et al., 2015). It would also be interesting to conduct functional imaging studies aimed at determining whether MAD deactivates abnormally activated networks (as in studies of MAD to relieve experimental inspiratory loading, (Hashimoto et al., 2006)) or activate the relief network (Peiffer et al., 2008).

\subsection{Possible implications}

An emerging body of evidence suggests that dyspnea can interfere with various types of cognitive tasks (Allard et al., 2017; Nierat et al., 2016; Vinckier et al., 2018). The underlying mechanisms are not yet clear, but both attentional effects and competition for cortical resources have been hypothesized to play a role. In OSAS patients, suppressed respiratory sensations are by nature unlikely to interfere with cognition through an attentional effect. However, our present data are compatible with the silent respiratory-related cortical activation shown before (Sharman et al., 2014): it would be interesting to test the hypothesis that a respiratory-related cortical activation could play a role in OSAS-related alterations of cognitive performances. A similar mechanism has been evidenced in a dyspnea-free patient suffering from congenital central alveolar hypoventilation and relying on cortical activation to maintain breathing during wakefulness (Sharman et al., 2014). From a clinical point of view, the absence of breathing discomfort deprives OSAS patients from a strong incentive to seek medical attention. It would be interesting to test the screening value of actively looking for breathing discomfort induced by the supine position (and possibly for breathing improvement by active mandibular advancement) in patients suspect of having OSAS on clinical grounds. OSA phenotypic traits may help to personalize the OSA treatment (Messineo et al., 2017), however assessing phenotype is not easily feasible in routine practice, as it requires Pcrit measurement during sleep (Wellman et al., 2011). In our study, the VAS-3 scale was correlated to awake Pcrit, and could be proposed as a simple tool to assess the phenotype of OSA in routine practice. 


\section{Acknowledgements}

The authors are grateful to Mr Anthony Saul, professional medical translator and editor, for his help with English style and grammar, Dr Jean-Baptiste Maranci for figure 1 artwork and $\mathrm{Mr}$ Sylvain Persohn and Mr Baptiste Sandoz for their support for micro CT scan assessments (Arts et Metiers ParisTech, IBHGC, 151 bd de l'Hopital 75013 PARIS - FRANCE).

\section{Author Contributions Statement}

VA, TS and JMC contributed substantially to the study design, data analysis and interpretation, and the writing of the manuscript. OJ, SS, IA, PG, IR, JBK and CMP contributed substantially to the data analysis and interpretation, and the writing of the manuscript.

\section{Funding}

This research did not receive any specific grant from funding agencies in the public, commercial, or not-for-profit sectors

\section{Conflict of interest}

V. ATTALI reports personal fees from Resmed, personal fees from Nyxoah, outside the submitted work; I. Arnulf reports personal fees from UCB Pharma, personal fees from Novartis, outside the submitted work; C. Morélot-Panzini reports personal fees from Astra-Zeneca, personal fees from Chiesi, personal fees from Boehringer Ingelheim, personal fees from Novartis, personal fees from Philips, personal fees from ADEP, personal fees from SOS oxygene, outside the submitted work; T. Similowski reports personal fees from AstraZeneca, personal fees from Boerhinger Ingelheim France, personal fees from GSK, personal fees and non-financial support from NOVARTIS, personal fees from Lungpacer Inc. , personal fees from TEVA, personal fees from Chiesi, personal fees from Pierre Fabre, personal fees from Invacare, outside the submitted work; In addition, Dr. SIMILOWSKI has a patent about a "brainventilator interface to improve the detection of dyspnea" licensed to Air Liquide Medical 
Systems and MyBrainTechnology. JM. Collet, P. Goudot, I. Rivals, O. Jacq, JB Kerbrat and S. Souchet have nothing to disclose. 


\section{References}

Allard, E., Canzoneri, E., Adler, D., Morelot-Panzini, C., Bello-Ruiz, J., Herbelin, B., Blanke, O., Similowski, T., 2017. Interferences between breathing, experimental dyspnoea and bodily self-consciousness. Sci Rep 7, 9990.

Berry, R.B., Budhiraja, R., Gottlieb, D.J., Gozal, D., Iber, C., Kapur, V.K., Marcus, C.L., Mehra, R., Parthasarathy, S., Quan, S.F., Redline, S., Strohl, K.P., Davidson Ward, S.L., Tangredi, M.M., 2012. Rules for scoring respiratory events in sleep: update of the 2007 AASM Manual for the Scoring of Sleep and Associated Events. Deliberations of the Sleep Apnea Definitions Task Force of the American Academy of Sleep Medicine. Journal of clinical sleep medicine : JCSM : official publication of the American Academy of Sleep Medicine 8, 597619.

Bonini, M., Fiorenzano, G., 2017. Exertional dyspnoea in interstitial lung diseases: the clinical utility of cardiopulmonary exercise testing. Eur Respir Rev 26.

Bosshard, V., Masse, J.F., Series, F., 2011. Prediction of oral appliance efficiency in patients with apnoea using phrenic nerve stimulation while awake. Thorax 66, 220-225.

Braem, M., 2015. In vitro retention of a new thermoplastic titratable mandibular advancement device. F1000Res 4, 56.

Bratton, D.J., Gaisl, T., Wons, A.M., Kohler, M., 2015. CPAP vs Mandibular Advancement Devices and Blood Pressure in Patients With Obstructive Sleep Apnea: A Systematic Review and Meta-analysis. JAMA 314, 2280-2293.

Davenport, P.W., Cruz, M., Stecenko, A.A., Kifle, Y., 2000. Respiratory-related evoked potentials in children with life-threatening asthma. Am J Respir Crit Care Med 161, 1830-1835.

Dematteis, M., Levy, P., Pepin, J.L., 2005. A simple procedure for measuring pharyngeal sensitivity: a contribution to the diagnosis of sleep apnoea. Thorax 60, 418-426.

Donzel-Raynaud, C., Redolfi, S., Arnulf, I., Similowski, T., Straus, C., 2009. Abnormal respiratory-related evoked potentials in untreated awake patients with severe obstructive sleep apnoea syndrome. Clinical physiology and functional imaging 29, 10-17.

Fauroux, B., Renault, F., Boelle, P.Y., Donzel-Raynaud, C., Nicot, F., Clement, A., Straus, C., Similowski, T., 2007. Impaired cortical processing of inspiratory loads in children with chronic respiratory defects. Respir Res 8, 61.

Gagnadoux, F., Nguyen, X.L., Le Vaillant, M., Priou, P., Meslier, N., Eberlein, A., KunDarbois, J.D., Chaufton, C., Villiers, B., Levy, M., Trzepizur, W., Launois, S., 2017. Comparison of titrable thermoplastic versus custom-made mandibular advancement device for the treatment of obstructive sleep apnoea. Respir Med 131, 35-42.

Gakwaya, S., Melo-Silva, C.A., Borel, J.C., Rousseau, E., Masse, J.F., Series, F., 2014. Impact of stepwise mandibular advancement on upper airway mechanics in obstructive sleep apnea using phrenic nerve magnetic stimulation. Respir Physiol Neurobiol 190, 131-136.

Georges, M., Morawiec, E., Raux, M., Gonzalez-Bermejo, J., Pradat, P.-F., Similowski, T., Morélot-Panzini, C., 2016. Cortical drive to breathe in amyotrophic lateral sclerosis: a dyspnoea-worsening

defense? European Respiratory Journal, in press. 
Gold, A.R., Marcus, C.L., Dipalo, F., Gold, M.S., 2002. Upper airway collapsibility during sleep in upper airway resistance syndrome. Chest 121, 1531-1540.

Grippo, A., Carrai, R., Romagnoli, I., Pinto, F., Fanfulla, F., Sanna, A., 2011. Blunted respiratory-related evoked potential in awake obstructive sleep apnoea subjects: a NEP technique study. Clin Neurophysiol 122, 1562-1568.

Harper, R.M., Kumar, R., Macey, P.M., Ogren, J.A., Richardson, H.L., 2012. Functional neuroanatomy and sleep-disordered breathing: implications for autonomic regulation. Anatomical record 295, 1385-1395.

Hashimoto, K., Ono, T., Honda, E., Maeda, K., Shinagawa, H., Tsuiki, S., Hiyama, S., Kurabayashi, T., Ohyama, K., 2006. Effects of mandibular advancement on brain activation during inspiratory loading in healthy subjects: a functional magnetic resonance imaging study. Journal of applied physiology 100, 579-586.

Ingman, T., Nieminen, T., Hurmerinta, K., 2004. Cephalometric comparison of pharyngeal changes in subjects with upper airway resistance syndrome or obstructive sleep apnoea in upright and supine positions. European journal of orthodontics 26, 321-326.

Jacq, O., Arnulf, I., Similowski, T., Attali, V., 2017. Upper airway stabilization by osteopathic manipulation of the sphenopalatine ganglion versus sham manipulation in OSAS patients: a proof-of-concept, randomized, crossover, double-blind, controlled study. BMC Complement Altern Med 17, 546.

Jolley, C.J., Luo, Y.M., Steier, J., Rafferty, G.F., Polkey, M.I., Moxham, J., 2015. Neural respiratory drive and breathlessness in COPD. Eur Respir J 45, 355-364.

Jordan, A.S., McSharry, D.G., Malhotra, A., 2014. Adult obstructive sleep apnoea. Lancet 383, 736-747.

Kato, J., Isono, S., Tanaka, A., Watanabe, T., Araki, D., Tanzawa, H., Nishino, T., 2000. Dosedependent effects of mandibular advancement on pharyngeal mechanics and nocturnal oxygenation in patients with sleep-disordered breathing. Chest 117, 1065-1072.

Kikuchi, Y., Okabe, S., Tamura, G., Hida, W., Homma, M., Shirato, K., Takishima, T., 1994. Chemosensitivity and perception of dyspnea in patients with a history of near-fatal asthma. $\mathrm{N}$ Engl J Med 330, 1329-1334.

Launois, C., Attali, V., Georges, M., Raux, M., Morawiec, E., Rivals, I., Arnulf, I., Similowski, T., 2015. Cortical Drive to Breathe during Wakefulness in Patients with Obstructive Sleep Apnea Syndrome. Sleep 38, 1743-1749.

Lin, C.C., Wu, K.M., Chou, C.S., Liaw, S.F., 2004. Oral airway resistance during wakefulness in eucapnic and hypercapnic sleep apnea syndrome. Respiratory physiology \& neurobiology $139,215-224$.

Macey, K.E., Macey, P.M., Woo, M.A., Henderson, L.A., Frysinger, R.C., Harper, R.K., Alger, J.R., Yan-Go, F., Harper, R.M., 2006. Inspiratory loading elicits aberrant fMRI signal changes in obstructive sleep apnea. Respiratory physiology \& neurobiology 151, 44-60.

Macey, P.M., Henderson, L.A., Macey, K.E., Alger, J.R., Frysinger, R.C., Woo, M.A., Harper, R.K., Yan-Go, F.L., Harper, R.M., 2002. Brain morphology associated with obstructive sleep apnea. American journal of respiratory and critical care medicine 166, 1382-1387.

Macey, P.M., Sarma, M.K., Nagarajan, R., Aysola, R., Siegel, J.M., Harper, R.M., Thomas, M.A., 2016. Obstructive sleep apnea is associated with low GABA and high glutamate in the insular cortex. J Sleep Res 25, 390-394. 
Marklund, M., Verbraecken, J., Randerath, W., 2012. Non-CPAP therapies in obstructive sleep apnoea: mandibular advancement device therapy. The European respiratory journal 39, 12411247.

Messineo, L., Magri, R., Corda, L., Pini, L., Taranto-Montemurro, L., Tantucci, C., 2017. Phenotyping-based treatment improves obstructive sleep apnea symptoms and severity: a pilot study. Sleep Breath 21, 861-868.

Mezzanotte, W.S., Tangel, D.J., White, D.P., 1992. Waking genioglossal electromyogram in sleep apnea patients versus normal controls (a neuromuscular compensatory mechanism). The Journal of clinical investigation 89, 1571-1579.

Milano, F., Mondini, S., Billi, M.C., Gobbi, R., Gracco, A., Sorrenti, G., 2013. The impact of a multidisciplinary approach on response rate of mandibular advancing device therapy in patients with obstructive sleep apnoea syndrome. Acta Otorhinolaryngol Ital 33, 337-342.

Morawiec, E., Raux, M., Kindler, F., Laviolette, L., Similowski, T., 2015. Expiratory load compensation is associated with electroencephalographic premotor potentials in humans. Journal of applied physiology 118, 1023-1030.

Nierat, M.C., Demiri, S., Dupuis-Lozeron, E., Allali, G., Morelot-Panzini, C., Similowski, T., Adler, D., 2016. When Breathing Interferes with Cognition: Experimental Inspiratory Loading Alters Timed Up-and-Go Test in Normal Humans. PloS one 11, e0151625.

Pang, P.S., Lane, K.A., Tavares, M., Storrow, A.B., Shen, C., Peacock, W.F., Nowak, R., Mebazaa, A., Laribi, S., Hollander, J.E., Gheorghiade, M., Collins, S.P., 2017. Is there a clinically meaningful difference in patient reported dyspnea in acute heart failure? An analysis from URGENT Dyspnea. Heart Lung 46, 300-307.

Patil, S.P., Punjabi, N.M., Schneider, H., O'Donnell, C.P., Smith, P.L., Schwartz, A.R., 2004. A simplified method for measuring critical pressures during sleep in the clinical setting. Am J Respir Crit Care Med 170, 86-93.

Peiffer, C., Costes, N., Herve, P., Garcia-Larrea, L., 2008. Relief of dyspnea involves a characteristic brain activation and a specific quality of sensation. American journal of respiratory and critical care medicine $177,440-449$.

Penzel, T., Moller, M., Becker, H.F., Knaack, L., Peter, J.H., 2001. Effect of sleep position and sleep stage on the collapsibility of the upper airways in patients with sleep apnea. Sleep 24, 9095.

Raux, M., Ray, P., Prella, M., Duguet, A., Demoule, A., Similowski, T., 2007. Cerebral cortex activation during experimentally induced ventilator fighting in normal humans receiving noninvasive mechanical ventilation. Anesthesiology 107, 746-755.

Reilly, C.C., Jolley, C.J., Elston, C., Moxham, J., Rafferty, G.F., 2016. Blunted perception of neural respiratory drive and breathlessness in patients with cystic fibrosis. ERJ Open Res 2.

Reilly, C.C., Ward, K., Jolley, C.J., Lunt, A.C., Steier, J., Elston, C., Polkey, M.I., Rafferty, G.F., Moxham, J., 2011. Neural respiratory drive, pulmonary mechanics and breathlessness in patients with cystic fibrosis. Thorax 66, 240-246.

Rosenzweig, I., Glasser, M., Polsek, D., Leschziner, G.D., Williams, S.C., Morrell, M.J., 2015. Sleep apnoea and the brain: a complex relationship. The Lancet. Respiratory medicine 3, 404414. 
Saboisky, J.P., Butler, J.E., McKenzie, D.K., Gorman, R.B., Trinder, J.A., White, D.P., Gandevia, S.C., 2007. Neural drive to human genioglossus in obstructive sleep apnoea. J Physiol 585, 135-146.

Sam, K., Lam, B., Ooi, C.G., Cooke, M., Ip, M.S., 2006. Effect of a non-adjustable oral appliance on upper airway morphology in obstructive sleep apnoea. Respiratory medicine 100, 897-902.

Schwartz, A.R., Smith, P.L., Wise, R.A., Gold, A.R., Permutt, S., 1988. Induction of upper airway occlusion in sleeping individuals with subatmospheric nasal pressure. J Appl Physiol (1985) 64, 535-542.

Series, F., Wang, W., Similowski, T., 2009. Corticomotor control of the genioglossus in awake OSAS patients: a transcranial magnetic stimulation study. Respir Res 10, 74.

Sharman, M., Gallea, C., Lehongre, K., Galanaud, D., Nicolas, N., Similowski, T., Cohen, L., Straus, C., Naccache, L., 2014. The cerebral cost of breathing: an FMRI case-study in congenital central hypoventilation syndrome. PloS one 9, e107850.

Steier, J., Jolley, C.J., Seymour, J., Ward, K., Luo, Y.M., Polkey, M.I., Moxham, J., 2010. Increased load on the respiratory muscles in obstructive sleep apnea. Respiratory physiology \& neurobiology 171, 54-60.

Stoeckel, M.C., Esser, R.W., Gamer, M., Buchel, C., von Leupoldt, A., 2015. Brain mechanisms of short-term habituation and sensitization toward dyspnea. Front Psychol 6, 748.

Su, M.C., Chiu, K.L., Ruttanaumpawan, P., Shiota, S., Yumino, D., Redolfi, S., Haight, J.S., Bradley, T.D., 2008. Lower body positive pressure increases upper airway collapsibility in healthy subjects. Respiratory physiology \& neurobiology 161, 306-312.

Su, M.C., Chiu, K.L., Ruttanaumpawan, P., Shiota, S., Yumino, D., Redolfi, S., Haight, J.S., Yau, B., Lam, J., Bradley, T.D., 2009. Difference in upper airway collapsibility during wakefulness between men and women in response to lower-body positive pressure. Clin Sci (Lond) 116, 713-720.

Subhan, M.M., Butler, T.J., Reed, J.W., 2003. Effect of repetitive exercise testing on breathlessness in humans. Clin Sci (Lond) 105, 243-250.

Sunnergren, O., Brostrom, A., Svanborg, E., 2011. Soft palate sensory neuropathy in the pathogenesis of obstructive sleep apnea. The Laryngoscope 121, 451-456.

Tsai, Y.J., Ramar, K., Liang, Y.J., Chiu, P.H., Powell, N., Chi, C.Y., Lung, T.C., Wen-Yang Lin, W., Tseng, P.J., Wu, M.Y., Chien, K.C., Weaver, E.M., Lee, F.P., Lin, C.M., Chen, K.C., Chiang, R.P., 2013. Peripheral neuropathology of the upper airway in obstructive sleep apnea syndrome. Sleep medicine reviews 17, 161-168.

Tun, Y., Hida, W., Okabe, S., Kikuchi, Y., Kurosawa, H., Tabata, M., Shirato, K., 2000. Inspiratory effort sensation to added resistive loading in patients with obstructive sleep apnea. Chest 118, 1332-1338.

Vecchierini, M.F., Attali, V., Collet, J.M., d'Ortho, M.P., El Chater, P., Kerbrat, J.B., Leger, D., Monaca, C., Monteyrol, P.J., Morin, L., Mullens, E., Pigearias, B., Meurice, J.C., 2016. A custom-made mandibular repositioning device for obstructive sleep apnoea-hypopnoea syndrome: the ORCADES study. Sleep medicine 19, 131-140.

Verburg, F.E., Bollen, K.H.A., Donker, H.J., Kramer, G.J.C., 2018. The effectiveness of two types of MADS for OSA therapy. Clin Oral Investig 22, 1995-2003. 
Verin, E., Petelle, B., Raux, M., Vincent, G., Fleury, B., Similowski, T., 2006. Effects of mandibular advancement on upper airway dynamics in awake normal subjects: a pilot study with phrenic nerve stimulation. Sleep medicine 7, 368-373.

Verin, E., Tardif, C., Buffet, X., Marie, J.P., Lacoume, Y., Andrieu-Guitrancourt, J., Pasquis, P., 2002. Comparison between anatomy and resistance of upper airway in normal subjects, snorers and OSAS patients. Respir Physiol 129, 335-343.

Vinckier, F., Morelot-Panzini, C., Similowski, T., 2018. Dyspnoea modifies the recognition of fearful expressions by healthy humans. The European respiratory journal 51.

von Leupoldt, A., Sommer, T., Kegat, S., Eippert, F., Baumann, H.J., Klose, H., Dahme, B., Buchel, C., 2009. Down-regulation of insular cortex responses to dyspnea and pain in asthma. American journal of respiratory and critical care medicine 180, 232-238.

von Leupoldt, A., Vovk, A., Bradley, M.M., Lang, P.J., Davenport, P.W., 2011. Habituation in neural processing and subjective perception of respiratory sensations. Psychophysiology 48, 808-812.

Walsted, E.S., Faisal, A., Jolley, C.J., Swanton, L.L., Pavitt, M.J., Luo, Y.M., Backer, V., Polkey, M.I., Hull, J.H., 2018. Increased respiratory neural drive and work of breathing in exercise-induced laryngeal obstruction. Journal of applied physiology 124, 356-363.

Wan, L., Van Diest, I., De Peuter, S., Bogaerts, K., Van den Bergh, O., 2009. Repeated breathlessness experiences induced by hypercapnia: differential effects on intensity and unpleasantness. Chest 135, 455-461.

Wellman, A., Eckert, D.J., Jordan, A.S., Edwards, B.A., Passaglia, C.L., Jackson, A.C., Gautam, S., Owens, R.L., Malhotra, A., White, D.P., 2011. A method for measuring and modeling the physiological traits causing obstructive sleep apnea. J Appl Physiol (1985) 110, 1627-1637. 


\section{Tables}

Table 1: Characteristics of OSAS patients and MAD titration

\begin{tabular}{|c|c|c|c|}
\hline & OSAS & Non OSAS & $\mathrm{p}$ \\
\hline & $\mathrm{N}=57$ & $\mathrm{~N}=12$ & \\
\hline Age (years) & $57[48 ; 64]$ & $52[39-59]$ & 0.12 \\
\hline Gender $(\mathrm{M} / \mathrm{F})$ & $40 / 17$ & $7 / 5$ & 0.42 \\
\hline BMI $\left(\mathrm{kg} / \mathrm{m}^{2}\right)$ & $28[25 ; 30]$ & $27[24-30]$ & 0.54 \\
\hline $\mathrm{BMI} \geq 30 \mathrm{~kg} / \mathrm{m} 2$ ( $\%$ of patients $)$ & 32 & 25 & 0.35 \\
\hline Baseline AHI (/h) & $25[20 ; 40]$ & $4[2-8]$ & $<0.0001$ \\
\hline AHI>30/h ( $\%$ of patients) & 40 & 0 & $<0.0001$ \\
\hline Desaturation index $\geq 3 \%(/ h)$ & $20[12 ; 30]$ & $1[0-3]$ & $<0.0001$ \\
\hline$\% \mathrm{SpO}_{2}<90 \%(\%)$ & $2[0 ; 4]$ & $0[0-0]$ & 0.006 \\
\hline Epworth (/24) & $11[8 ; 13]$ & $15[9 ; 18]$ & 0.08 \\
\hline Maximal mouth opening (mm) & $43[40 ; 50]$ & ND & \\
\hline MA from end to end in maximum protrusion $(\mathrm{mm})$ & $5.0[4.0 ; 7.0]$ & $5.0[5.0 ; 5.0]$ & 0.55 \\
\hline Dental overjet (mm) & $3.0[2.0 ; 4.0]$ & $2.0[1.0 ; 3.0]$ & 0.15 \\
\hline Maximum jaw protrusion (mm) & $8.0[7.0 ; 9.0]$ & $7.0[6.0 ; 7.0]$ & 0.053 \\
\hline Dental overbite (mm) & $3.0[2.0 ; 4.0]$ & ND & \\
\hline Midline deviation in maximum protrusion (nb) & 7 & 0 & 0.34 \\
\hline Type of MAD Somnodent/Narval/ BluePro® & $11 / 46 / 0$ & $0 / 0 / 12$ & \\
\hline MA (mm) & $7.0[6.0 ; 7.0]$ & $6.5[6.0 ; 7.0]$ & 0.81 \\
\hline MA (\% of maximal MA) & $80[75 ; 89]$ & $100[97 ; 100]$ & 0.005 \\
\hline AHI with MAD at the 3 -month follow-up $(/ \mathrm{h})$ & $9.0[5.0 ; 14.0]$ & ND & \\
\hline
\end{tabular}

Values are median and interquartile range, or when specified, \% or number (nb). BMI, body mass index; AHI, apnoea-hypopnoea index; SpO2, transcutaneous oxygen saturation by pulse oximetry; MA, Mandibular Advancement ; ND, Not Done 
Table 2: Univariate predictors of changes in respiratory comfort with MAD (variation of VAS-3 $\geq 20 \%$ )

\begin{tabular}{|llll|}
\hline & $\begin{array}{l}\text { Improvement } \\
(\mathrm{n}=37)\end{array}$ & $\begin{array}{l}\text { No change } \\
(\mathrm{n}=20)\end{array}$ & $\mathrm{p}$ \\
BMI $\left(\mathrm{kg} / \mathrm{m}^{2}\right)$ & 28.0 & 25.5 & $1.05 \mathrm{e}-01$ \\
Maximal mouth opening $(\mathrm{mm})$ & 46.0 & 41.0 & $1.71 \mathrm{e}-03$ \\
$\begin{array}{l}\text { Midline deviation in maximum } \\
\text { protrusion }(\mathrm{mm})\end{array}$ & 5.4 & 25.0 & $8.37 \mathrm{e}-02$ \\
Supine VAS-1 $(\mathrm{mm})$ & 14.0 & 5.0 & $6.25 \mathrm{e}-02$ \\
Supine VAS-2 $(\%)$ & -12.0 & 0.0 & $1.37 \mathrm{e}-01$ \\
Desaturation index $\geq 3 \%$ on MAD $(/ \mathrm{h})$ & 9.4 & 4.2 & $1.60 \mathrm{e}-01$ \\
MAD discontinuation $(\%$ patients $)$ & 5.4 & 20.0 & $1.70 \mathrm{e}-01$ \\
\hline
\end{tabular}

BMI, body mass index; VAS, Visual Analogic Scale; MAD, Mandibular Advancement Device 


\section{Figure legends}

Figure 1. Psychophysiological evaluation of breathing discomfort with visual analogic scales (VAS).

VAS-1 was on a non-graduated 100-mm visual analogue scale anchored by "no breathing discomfort" at the left end, and "intolerable breathing discomfort" at the right end. VAS-2 was a non-graduated $100-\mathrm{mm}$ visual transitional analogue scale aiming at evaluating the changes in breathing comfort between the sitting and the supine positions: "extreme deterioration" on the left end (with a "_“sign), to "extreme improvement" on the right (with a "+" sign), with a middle marker to indicate "no change". VAS-3 was a similar non graduated 100-mm visual transitional analogue scale to evaluate the changes in breathing comfort between the supine position witout and then with the mandibular advancement device.

Figure 2. Breathing discomfort at baseline evaluated in the sitting and supine positions.

VAS-1 was on a non-graduated 100-mm visual analogue scale anchored by "no breathing discomfort" at the left end, and "intolerable breathing discomfort" at the right end. VAS-2 was a non-graduated 100-mm visual transitional analogue scale aiming at evaluating the changes in breathing comfort between the sitting and the supine positions: "extreme deterioration" on the left end (with a "_“ sign), to "extreme improvement" on the right (with a "+” sign), with a middle marker to indicate "no change".

Figure 3. Improvement of breathing comfort with the mandibular advancement device. Improvement of breathing comfort with the mandibular advancement device in the supine position, evaluated by the transitional visual analogue scale (VAS-3) respectively, in all patients, in patients with deteriorated breathing comfort in the supine position (VAS-2 supine 
$\leq-20 \%$, and in patients without deterioration of breathing comfort in the supine position (VAS2 supine $>-20 \%$ ). VAS-2 was a non-graduated $100-\mathrm{mm}$ visual transitional analogue scale aiming at evaluating the changes in breathing comfort between the sitting and the supine positions: "extreme deterioration" on the left end (with a "_" sign), to "extreme improvement" on the right (with a "+" sign), with a middle marker to indicate "no change". VAS-3 was a similar non graduated $100-\mathrm{mm}$ visual transitional analogue scale to evaluate the changes in breathing comfort between the supine position without and then with the mandibular advancement device.

Figure 4. Spearman's correlation between the change in critical upper airway closing pressure (awake Pcrit, as percent of baseline) induced by the mandibular advancement device and the corresponding variation of respiratory sensations in the supine position (VAS-3).

Supplemental material. Micro-computed tomography* of the three mandibular advancement devices. * $\mu$ CT100; ScancoMedical; Brüttisellen, Switzerland 
Presence of breathing discomfort at rest?

\section{YES or NO}

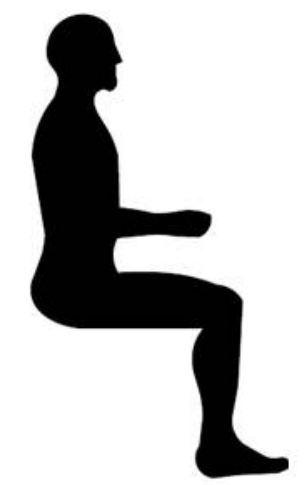

VAS-1 seated
3

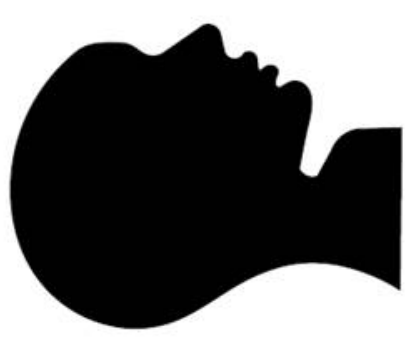

VAS-1 supine
No

breathing

discomfort
Intolerable

breathing discomfort
No

breathing

discomfort

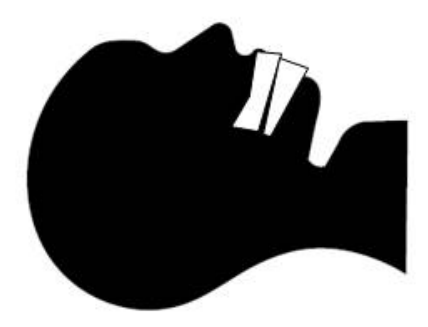

VAS-2 supine vs seated

Extreme deterioration
Extreme improvement
VAS-3 supine MAD vs without

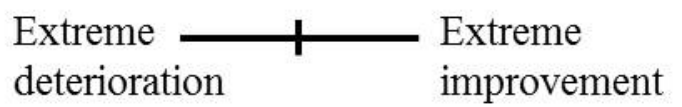
improvement 


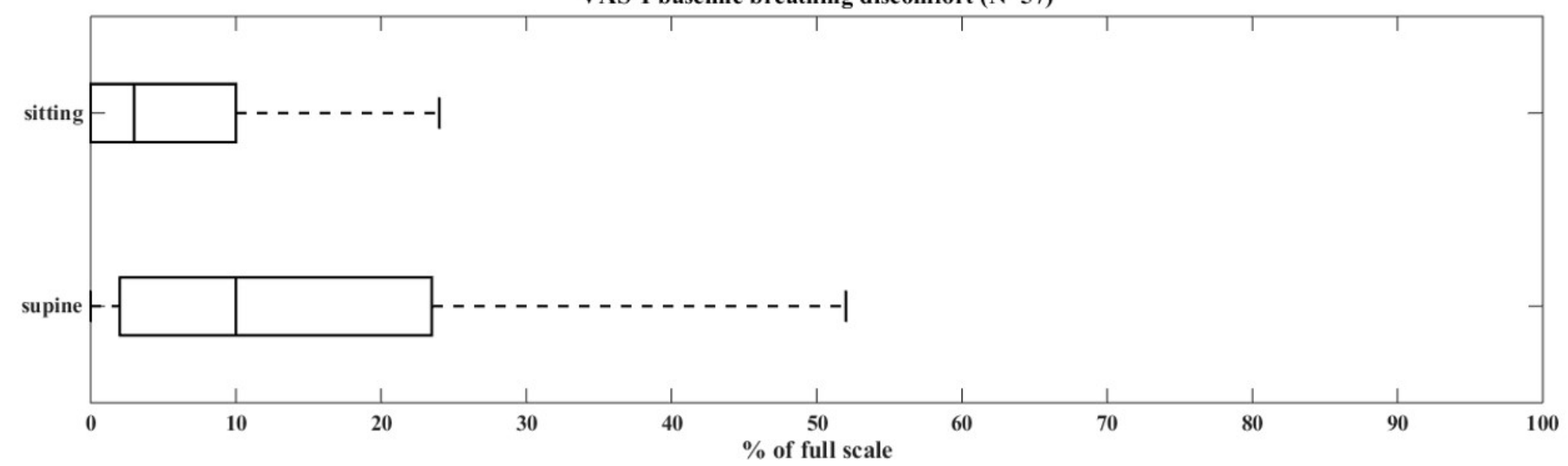

VAS-2 transition from sitting to supine ( $N=57$ )

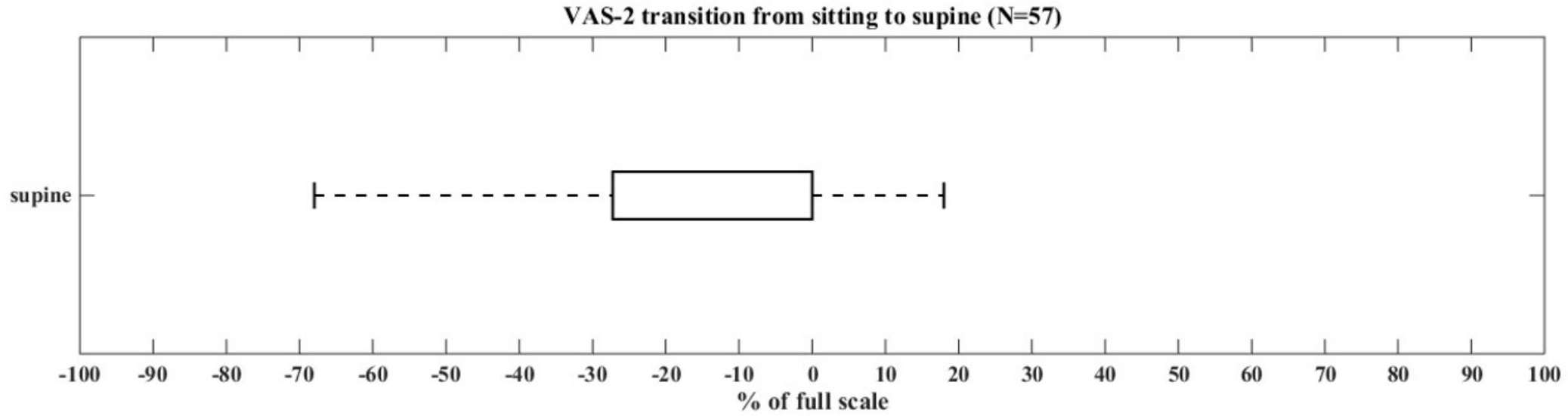




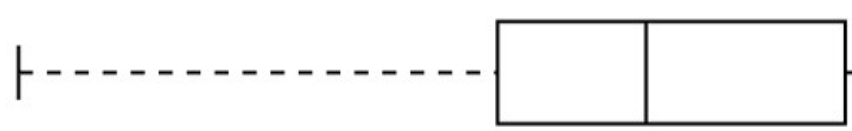

Patients with VAS-2 supine $>-20 \% \quad(n=38)$

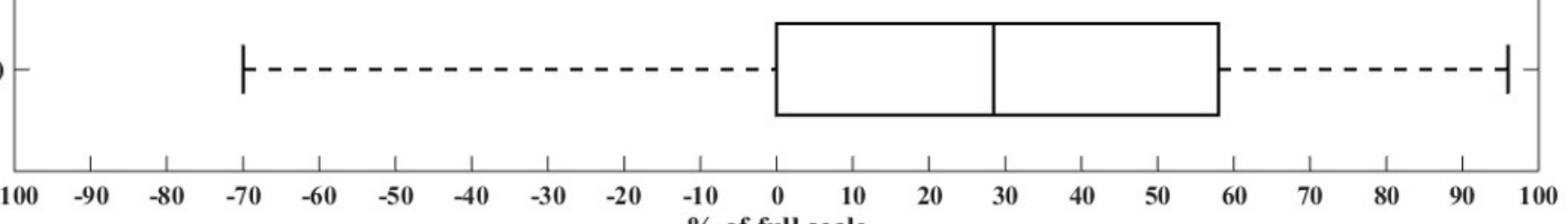




\section{Micro-computed tomography* of the three mandibular adancement devices}

Narval ${ }^{\mathrm{TM}}$ custom-made device,

(ResMed, Saint-Priest, France)

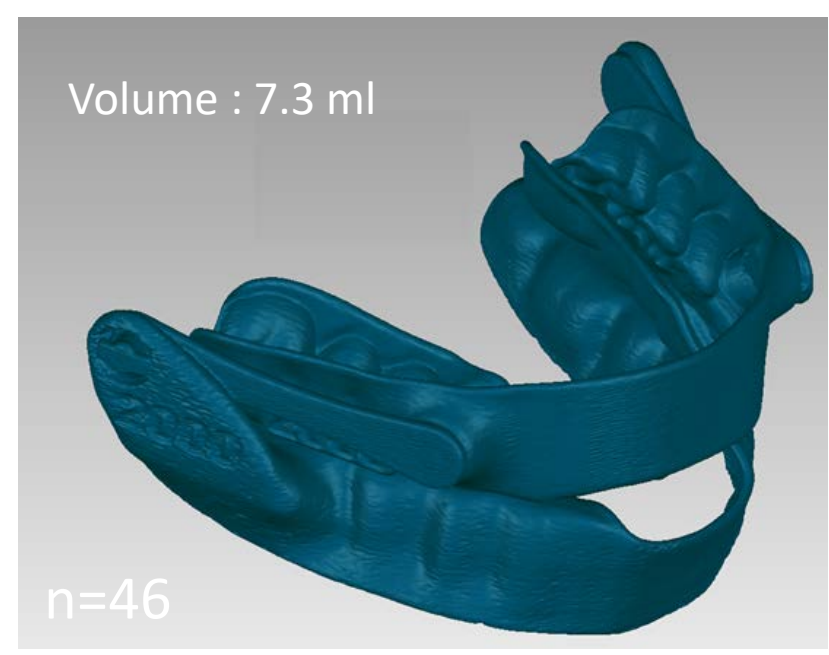

Somnodent ${ }^{\mathrm{TM}}$ custom-made device,

(SomnoMed Ltd., Sydney, Australia)

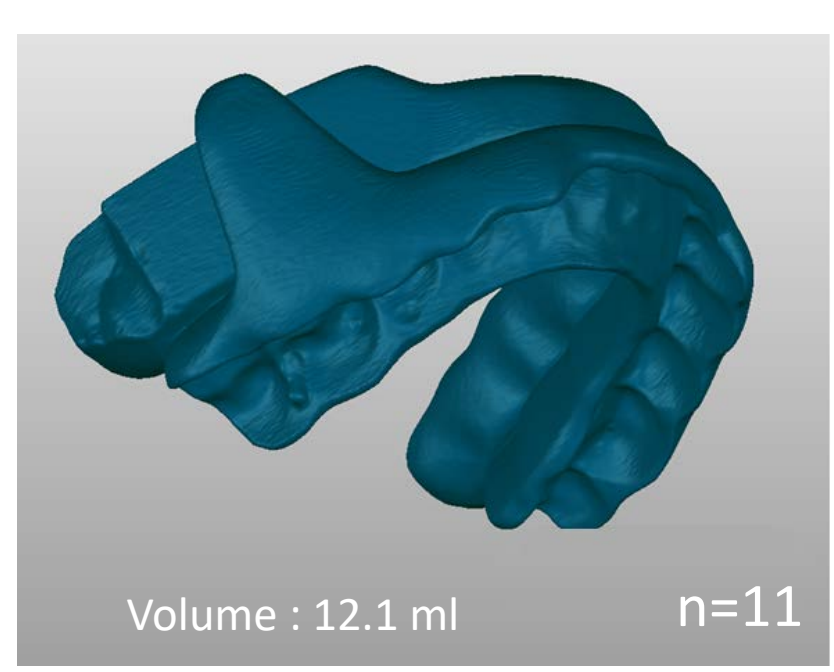

OSAS group $\mathrm{N}=57$

BluePro ${ }^{\circledR}$ titratable thermoplastic device (BlueSom, Orvault, France)

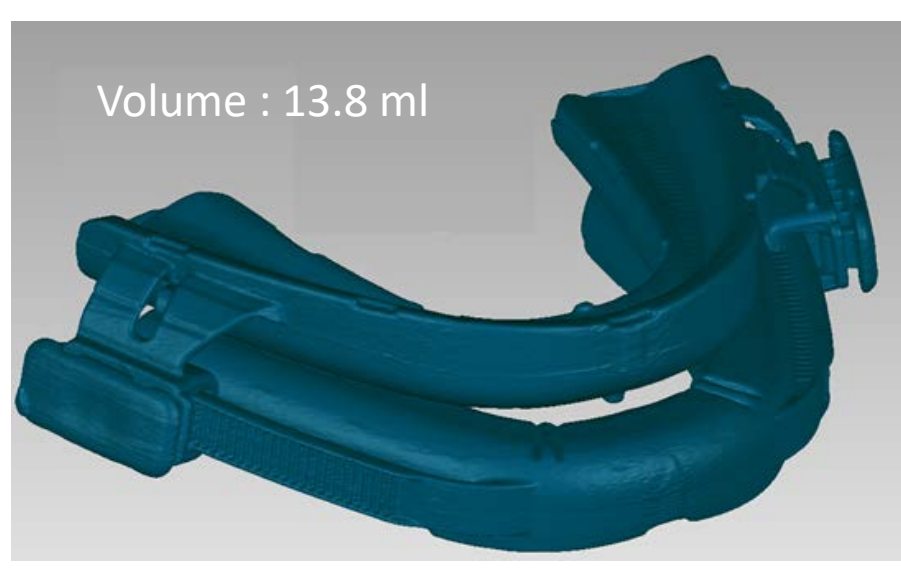

Control Group N=12 